\title{
Editorial
}

\section{Vacunación y desarrollo en tiempos de la COVID-19}

http://doi.org/10.14718/revfinanzpolitecon.v13.n1.2021.1

\section{Joan Miguel Tejedor-Estupiñán*}

La pandemia generada por el virus SARS-CoV-2 ha dejado, hasta diciembre de 2020, alrededor de 100.000.000 de contagiados y 2.000.000 de víctimas mortales alrededor del mundo (Johns Hopkins University y Medicine, 2020). Sin embargo, como lo advertían científicos y políticos de todo el mundo, las consecuencias de esta pandemia develarían, por un lado, las debilidades de los sistemas de salud de las naciones a la hora de enfrentar este tipo de amenazas globales y, por otro, el nivel de respuesta del sector público y el mercado ante efectos sociales colaterales causados por las medidas de protección impuestas a nivel global desde la Organización Mundial de la Salud.

A un año de haber sido detectado el primer caso de la enfermedad COVID-19 en la ciudad de Wuhan, China, los efectos generados por la dispersión del virus en los países han sido disímiles, dependiendo del sistema político, la estructura económica, la cultura $y$, en especial, el nivel de desarrollo. Los efectos colaterales de esta pandemia han impactado a las diversas esferas de la economía local, regional y mundial, como ha sucedido con el empleo. Otro impacto - no menos importante- es la salud mental, sobre todo de las poblaciones más vulnerables y en situación de pobreza y extrema pobreza. Al mismo tiempo, pareciera que la delincuencia y las diferentes formas de violencia se acrecentaran en medio de las medidas tomadas por los gobiernos para disminuir los contagios y no colapsar los sistemas de salud.

Mientras que algunos países desarrollados, como Alemania y Japón, cuentan con 8 y 13 camas de hospital por cada mil habitantes en promedio, hay casos como el de Estados Unidos, que tiene en promedio 2,9 camas por cada mil habitantes; o países de la Unión Europea como Italia y España cuentan con 3,1 y 3 camas por cada mil habitantes, respectivamente. Solo por mencionar algunos países en vía de desarrollo, encontramos que India,

1 Ph.D. (C) en Economía; Magíster en Derechos Humanos y Economista. Editor de la revista Finanzas y Política Económica de la Universidad Católica de Colombia. Dirección de correspondencia: Facultad de Economía, Universidad Católica de Colombia, Carrera 13 n. 47-49 (Bogotá, Colombia).Correo electrónico: jmtejedor@ ucatólica.edu.co. (D) ORCID: https://orcid.org/0000-0002-2346-3222 
Haití y Colombia cuentan apenas con 0,5, 0,7 y 1,7 camas de hospital por cada mil habitantes, respectivamente (Banco Mundial, 2020). Estas cifran evidencian que incluso en los países desarrollados los sistemas de salud pueden colapsar en el contexto de una pandemia, y más aún dejan clara la falta de inversión en este sector, en especial en los países en vía de desarrollo.

Frente a las magnitudes alcanzadas por la emergencia global, la reacción de las naciones fue distinta. La mayoría de países se han trazado como objetivo aumentar los niveles de gasto público para mitigar los impactos de las medidas de contención de propagación del coronavirus en las economías. La Organización para la Cooperación y el Desarrollo Económicos (OCDE) afirma que sus integrantes han anunciado apoyo financiero para las empresas y estrategias para complementar los ingresos de los trabajadores más afectados por la crisis. Japón, Reino Unido, EE. UU. y Suiza, por ejemplo, planean invertir el equivalente a $21,1 \%, 12,8 \%, 11,0 \%$ y 9,3\% del PIB, respectivamente, en áreas que incluyen préstamos para las pymes, seguros de desempleo, indemnizaciones por pérdida de ingreso, material sanitario, aviación y cultura. Mientras que países como Irlanda, Turquía, España, Colombia e Italia apenas invertirán una proporción del PIB equivalente al 2\%, 2\%, 1,6\%, 1,5\% y 1,4\%, respectivamente (Turuban, 2020).

En el caso de China, se ha optado por construir más de 6 hospitales con capacidad de 1500 camas cada uno, en diferentes regiones, impresionando con la rapidez de construcción: en un tiempo de 5 a 10 días (La Vanguardia, 2021). En junio de 2020, en El Salvador se inauguró un hospital exclusivo para el tratamiento de pacientes afectados por la COVID-19, con una capacidad para albergar hasta 2000 camas, la mitad de ellas de cuidados intensivos (Europa Press, 2020). En marzo de 2020, en Bogotá, Colombia, por mandato de su alcaldesa, se pagó un contrato de alrededor de US\$1.000.000 para tomar en arriendo un escenario de eventos masivos, que se adecuó con más de 200 camas UCI para pacientes asintomáticos, con una inversión total de alrededor de US\$ 56.000.000 (Secretaría de Salud de Bogotá, 2020). Sin embargo, no se tuvo en cuenta que el pico de la pandemia para este país estaba previsto para los meses de agosto a diciembre, y ello ha evidenciado la falta de planeación e incluso derivado en investigaciones por posibles manejos de corrupción (Pérez Díaz, 2021). En algunas naciones, los parlamentarios aún debaten la propuesta para la creación de un ingreso básico para mitigar los impactos de los confinamientos prolongados en el empleo y la pobreza.

El ranking de resiliencia de la COVID-19 de Bloomberg analiza una variedad de datos para obtener una mejor comprensión de dónde se está manejando la pandemia de la manera más eficaz, con la menor perturbación social y económica, clasificando los 
mejores y peores países para pasar la pandemia. Por un lado, este ranking clasifica a Nueva Zelanda, Singapur y Australia como los tres mejores países para estar en esta pandemia; por otro lado, México, Sudáfrica y Colombia se ubican como los peores lugares para estar localizados en estos tiempos pandémicos.

Con relación al plan de vacunación global, actualmente la tecnología alcanzada por la humanidad permitió que Rusia registrara la primera vacuna en agosto de 2020, a tan solo ocho meses de haberse descubierto el virus en Wuhan, una proeza que hace cien años, en épocas de la gripe española, no hubiera sido posible, pues no existen antecedentes de que se haya desarrollado una vacuna para algun patógeno de manera tan pronta. Con el registro de nuevas vacunas por parte de algunos países desarrollados, representantes de diferentes sectores en todo el mundo advierten la creación de una especie de nacionalismo con relación a la producción y acceso a las vacunas, lo cual se observa en la concentración de tecnología y patentes para su producción en países de ingresos altos: Rusia (Sputnik V), EE. UU. (Moderna), Alemania (BioNTech-Pfizer), China (Sinopharm y Sinovac), Suecia y Gran Bretaña (Oxford-AstraZeneca) e India (Covaxin). Se estima además que un $95 \%$ de las vacunas contra la COVID-19 inicialmente fueron acaparados por 10 países (DW, 2021): Estados Unidos, China, Reino Unido, Israel, Emiratos Árabes Unidos, Italia, Rusia, Alemania, España y Canadá. Mientras tanto, los países en vía de desarrollo, por un lado, están comprando vacunas a los diferentes distribuidores y, por el otro, claman porque se liberen las patentes y se permita acceder a la tecnología para la producción de estas.

Las farmacéuticas han presentado los costos estimados de sus vacunas contra el coronavirus. La más barata es la de AstraZeneca, con un costo por dosis de US\$3; seguidas por la Sputnik V, US\$ 10; Pfizer, US\$ 20; Moderna, US\$ 25; Sinovac, US\$ 30 (Acosta Argote, 2021). Finalmente, dado que los países ricos tuvieron acceso primero a las vacunas que los países pobres, alrededor de 37 países de ingresos altos comenzaron sus jornadas de vacunación al iniciar el año 2021. En contraste, gran parte de países de ingresos medios e ingresos bajos comenzarán sus jornadas de vacunación para finales de 2022 y comienzos de 2023 (The Economist, 2021). Estos datos muestran cómo los países en vía de desarrollo vienen siendo los más afectados por los efectos colaterales de la pandemia, que han impactado negativamente, además de la salud física, la salud mental, la economía, el empleo e incluso la paz. Así, puede verse que en estos momentos se necesitan acuerdos globales que beneficien también a los países de ingresos medios y bajos, los cuales requieren más acción que promesas y nacionalismo de vacunas (Wintour, 2021).

En este primer número de la revista Finanzas y Política Económica del año 2021 contamos con investigaciones de autores provenientes de países como India, México, España, 
Editorial

Chile y Colombia, quienes, a pesar de las dificultades de estos tiempos, presentan a nuestros lectores diferentes contribuciones sobre temas relacionados con la COVID-19, la eficiencia financiera y sostenibilidad del gasto tanto público como privado, el comportamiento de los mercados financieros regionales, las políticas corporativas, entre otros temas que se suman a los aportes de otros investigadores de las áreas de las finanzas y las políticas económicas. La revista Finanzas y Política Económica extiende un especial agradecimiento a los autores y evaluadores de este número, y a todo el equipo editorial de la revista, por sus aportes en estas épocas de incertidumbre, la cual todos esperamos superar pronto.

\section{REFERENCIAS}

1. Acosta Argote, C. (2021). El panorama global de las dosis y los precios de las vacunas contra el virus covid-19. https://www.larepublica.co/globoeconomia/un-vistazo-al-panorama-global-delas-dosis-y-los-precios-de-vacunas-contra-el-covid-19-3108081

2. Banco Mundial. (2020). Camas hospitalarias (por cada 1.000 personas). https://datos.bancomundial.org/indicador/SH.MED.BEDS.ZS?view = chart

3. DW. (2021). Las vacunas contra el coronavirus: iquién las produce? ¿A quién se las van a aplicar? https://www.dw.com/es/las-vacunas-contra-el-coronavirus-quién-las-produce-a-quién-se-lasvan-a-aplicar/a-56150359

4. Europa Press. (2020). El Salvador inaugura un hospital solo para pacientes de la COVID-19 con una capacidad de 2.000 camas. https://www.europapress.es/internacional/noticia-salvadorinaugura-hospital-solo-pacientes-covid-19-capacidad-2000-camas-20200622041616.html

5. Johns Hopkins University y Medicine. (2020). COVID-19 Dashboard by the Center for Systems Science and Engineering at Johns Hopkins University. https://coronavirus.jhu.edu/map.html

6. La Vanguardia. (2021). China acaba en cinco días un hospital con 1.500 habitaciones para enfermos de COVID. https://www.lavanguardia.com/vida/20210116/6183700/china-hospitalesnangong-habei-covid-rebrotes.html

7. Pérez Díaz, V. (2021). Procuraduría no descarta iniciar investigación sobre el pabellón de salud en Corferias. https://www.asuntoslegales.com.co/actualidad/procuraduria-no-descarta -iniciar-investigacion-sobre-el-pabellon-de-salud-en-corferias-3110102

8. Secretaría de Salud de Bogotá. (2020). \$200 mil millones para adecuación hospitalaria de Corferias. http://www.saludcapital.gov.co/Paginas2/Noticia_Portal_Detalle.aspx?IP=1073

9. The Economist. (2021). Vaccine nationalism means that poor countries will be left behind. https:/www.economist.com/graphic-detail/2021/01/28/vaccine-nationalism-means-that-poor -countries-will-be-left-behind

10. Turuban, P. (2020). Suiza, uno de los países que más ayuda a su economía tras la COVID-19. https://www.swissinfo.ch/spa/crisis-sin-precedentes_suiza--uno-de-los-países-que-más-ayudaa-su-economía-tras-la-covid-19/45756692 
Editorial

11. Wintour, P. (2021). World's poor need action, not Covid 'vaccine nationalism', say experts. https:/www.theguardian.com/world/2021/jan/22/worlds-poor-need-action-not-covid-vaccine -nationalism-say-experts 